\title{
Management of Small Scale Fast Foods Industries in Delta State of Nigeria
}

\author{
Bridget Uyoyou Imonikebe \\ Home Economics Unit \\ Vocational Education Department \\ Delta state university, Abraka, Nigeria
}

\begin{abstract}
The study investigated the meal preparation and service practices of fast food providers in Delta State, Nigeria with a view of evolving adequate measures for improvement of such practices. The study area was Ethiope East Local Government Area. A sample of 57 fast food providers (managers) was obtained. Questionnaire was used for data collection. The mean, standard deviation and t-test were used for data analysis. Results showed that some of the hygiene practices adopted in meal preparation and services are as follows: Washing of hands with soap and clean water before preparing and serving food; cooking food sufficiently to kill germs; Using of clean napkins during meal preparation; Avoiding sneezing directly on food; Wearing of aprons while preparing and serving meals; Washing food before preparing it. Other practices are supervising the activities of the assistants; Reheating only the foods that will be served; Varying the methods of food preparation; Cutting of vegetables before washing; Cooking of meals with pressure cooker. It was recommended among others that the fast food managers should be given Nutrition and Health Education.
\end{abstract}

\section{Introduction}

At present, many people in Nigeria take up government jobs. Some are in private sectors. Some are traders, labourers while others do some other work. These workers usually work outside their home environment. The pressure of work on many people in Nigeria is on the increase. This could be due to strive for excellence. This has made many people to eat food outside their homes. Some people eat food outside their homes because of busy schedule and no enough time to cook. Many of these workers do not have enough time to prepare their meals before going to work. Some may eat at home while others due to the pressure of work may not have the opportunity to eat their meals at home. Most of these workers often resort to patronizing fast food providers. Presently, there is a proliferation of fast food services to the general public especially to those who may desire variety in their meals.

Fast foods are ready to-eat-foods. Food and Agricultural Organization (FAO) referred to fast foods as foods which are prepared and served quickly at fast food restaurants, shops, market, schools and other similar places [8]. Fast foods are inexpensive. They provide variety and include traditional foods.

FAO stated that the provision of fast foods involves the preparation and service of meals for consumption on the premises or off the premises normally requiring short amount of time between the period of ordering and serving of the food [8]. Federal Ministry of Health (FMH) stated that fast food industry has an important economic role and employs many persons [6]. It was stated that Nigeria has many fast food industries in urban areas.

The sales of fast foods are a booming business in Nigeria. It is being taken up by people as a venture towards self-reliance. There is much patronage of these fast food providers/vendors by consumers of varied degrees. In many cases, the demand for these foods ranging from snacks, soft drinks to major meals is very high. The demand is so high that the food vendors are not able to supply enough to meet the demand of their consumers.

The fast rate at which the meals are prepared, the possibility of food contamination cannot be ruled out. There is the possibility of not thoroughly washing utensils and equipment used for food preparation and service. Some fast foods are prepared in dirty environment. FAO [7] and UN [15] advised that the place or area of meal preparation and service should be far from sources of contamination, e.g rubbish heap, waste, dirty water and animals.

Some people do not clean their environment at point of sale. FAO [7] gave the advice that the area where food is sold must be kept clean, protected from the sun and wind. During meal preparation, the use of apron is necessary. WHO recommended the wearing of apron and hair covered with a cap during meal preparation [17]. WHO advised on the need of avoiding wearing rings and bracelet during food handling. The handing of food by persons with cuts and sore was highly discouraged.

Richard emphasized the fact that personal cleanliness must be maintained in food handling operations [13]. He stressed the need for the wearing of sanitary protective clothes and footwear and the covering of hair. He stated that such clothing must be clean. He advised that all persons who are food handlers must thoroughly wash hands with soap under warm running potable water. In addition Brook [3] stated that food handlers should always wash their hands with warm soapy water after using toilet facilities, blowing nose, sneezing or coughing, 
touching the face, hair, or any unwanted body part and after engaging in other activities that could easily contaminate one's hands. Oghenekome and Nwankwo found that some caterers and food vendors serve partially cooked food [10]. They recommended that food should be thoroughly cooked to destroy bacteria that may be present in the food. There is much concern on the safety of food consumed because good nutrition is needed for the promotion of good health status. Adequate nutrition is necessary if certain types of diseases are to be prevented.

Ene-Obong indicated that adequate nutrition is a prerequisite for the maintenance of good health [5]. The United States Food and Drug Administration stated that people who are suffering from certain diseases need to be very careful because their diseases or the food they eat may put them at risk for serious illness [16].

During food preparation/storage there is need to observe strictly the rules of hygiene if good health status is to be guaranteed. Hygiene is the maintenance of health and healthy living. It is a science that deals with the promotion and prevention ill-health [4]. Hygiene deals with the sanitary science which aims at producing food which is safe for consumption and of good keeping quality [12]. Oghenekome and Nwankwo indicated that when food is prepared without the observance of principles of food hygiene and if the food is not properly cooked, the food becomes infected with microorganisms [10]. Such microorganisms are pathogens. They stated that pathogens do not necessarily leave detectable odours or taste in food. As such it is impossible to ascertain if food is contaminated by perceiving the odour or tasting or by looking at it [13].

The consumption of contaminated food could result to having food borne diseases. In order to prevent such situation there is need to make frantic efforts to arrest the situations. There is need to examine the food handling practices of fast food providers in Delta State in a bid to satisfying their customers. There is need to identify food handling practices that could predispose consumers to ill health and then inform and educate these people. Hence, this study was carried out.

\section{Objectives of the study}

The study was meant to investigate the food handling practices (meal preparation and service practices) of fast foods providers in Delta State in Nigeria. The specific objectives of the study were as follows:

1. To investigate the hygiene practices of fast food providers in meal preparation and service in Delta State.
2. To identify the unsafe practices of fast food providers in meal preparation and service in Delta State.

\section{Methodology}

The study was a survey of the meal preparation and service practices of fast food providers in Delta State.

Population/Sample: The population of the study was made up of fast food providers in Delta State. A sample of 57 fast food providers in was involved in the study. These were randomly selected from Abraka in Ethiope East Local Government Areas of Delta State. Seventeen fast food providers were randomly selected from Delta State University Abraka and 40 from outside the campus. This made up a total of 57 fast food providers.

Instrument: Questionnaire was the instrument used for data collection. Section A was based on the meal preparation and service practices. Section B was on the unsafe measures of food preparation and service practices. These items were on a 3-point scale of always practiced, sometime practiced, never practiced representing 3,2 and 1 respectively.

Method of data collection: Fifty seven copies of the questionnaire were given to the subjects to respond to. After this, the copies of the questionnaire were immediately retrieved on the spot. All the copies of the questionnaire were retrieved and used for the study.

Method of data analysis: The total responses to each questionnaire item were put in frequency distribution tables. The percentages and mean of the items were calculated. From the 3-point scale, a mean of $2.00-3.00$ is a common practice while below 2.00 is not a common practice. T-test was used as the test statistics.

Table 1 showed that the items had their mean rating and above the cutoff point of 2 . This indicated that the items were common hygiene practices of the fast food handlers in terms of meal preparation and services in Ethiope East Local Government Area of Delta State. The other items with their mean values below 2 were not common practices of the fast food handlers. 
Table 1. Meal Preparation and service practices

\begin{tabular}{|c|c|c|c|c|c|c|}
\hline $\mathrm{S} / \mathrm{N}$ & $\begin{array}{l}\text { Hygiene Practices adopted in meal preparation and } \\
\text { services }\end{array}$ & 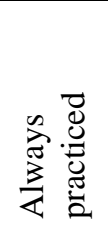 & 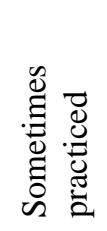 & 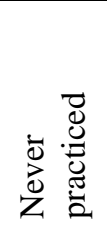 & 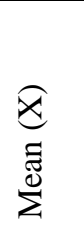 & 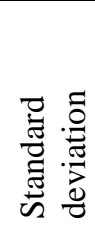 \\
\hline 1 & $\begin{array}{l}\text { Washing food properly before preparation; washing } \\
\text { of hands with soap and clean water before } \\
\text { preparing/serving meals }\end{array}$ & 42 & - & 3 & 2.87 & 0.50 \\
\hline 2 & Cooking food sufficiently to kill germs & 30 & 6 & - & 2.83 & 0.38 \\
\hline 3 & Using of clean napkins during meal preparation & 33 & 5 & 3 & 2.73 & 0.59 \\
\hline 4 & Avoiding sneezing directly on food & 32 & 9 & 4 & 2.62 & 0.65 \\
\hline 5 & $\begin{array}{l}\text { Wearing of clean apron while preparing/serving } \\
\text { meals }\end{array}$ & 21 & 5 & 13 & 2.21 & 0.92 \\
\hline 6 & Re-heating only the foods that will be served & 26 & 10 & 6 & 2.48 & 0.74 \\
\hline 7 & Keeping nails short & 25 & 17 & 4 & 2.47 & 0.66 \\
\hline 8 & Covering of hair during meal preparation/serving & 24 & 15 & - & 2.62 & 0.49 \\
\hline 9 & Avoidance of cleaning sweat with dish cloth & 16 & 12 & 15 & 2.07 & 0.86 \\
\hline \multirow[t]{2}{*}{10} & Avoiding of scratching of hair while cooking & 18 & 12 & 11 & 2.17 & 0.83 \\
\hline & Other meal preparation and services practices & & & & & \\
\hline 1 & Supervising the activities of assistants & 27 & 9 & - & 2.75 & 0.44 \\
\hline 2 & Varying the methods of food preparation & 27 & 14 & 3 & 2.55 & 0.63 \\
\hline 3 & Washing of leafy vegetables before cutting & 26 & 16 & - & 2.62 & 0.49 \\
\hline 4 & Cooking of meals with pressure cooker & 6 & 15 & 17 & 1.71 & 0.73 \\
\hline 5 & Keeping of hot food in a warmer before service & 15 & 14 & 9 & 2.16 & 0.78 \\
\hline 6 & $\begin{array}{l}\text { Storing of cold food (chilled) drinks in a cooler } \\
\text { before service }\end{array}$ & 12 & 15 & 14 & 1.95 & 0.80 \\
\hline
\end{tabular}


Table 2. Unsafe (unhygienic) food preparation practices

\begin{tabular}{|c|c|c|c|c|c|c|}
\hline $\mathrm{S} / \mathrm{N}$ & $\begin{array}{l}\text { Unsafe Practices adopted in meal preparation and } \\
\text { services }\end{array}$ & 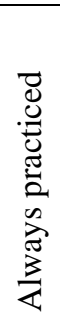 & 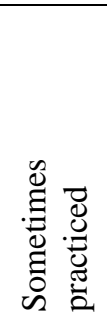 & 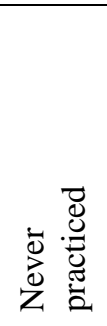 & 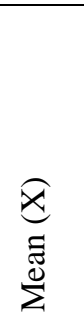 & 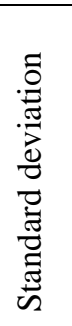 \\
\hline 1 & $\begin{array}{l}\text { Not Covering/dressing any wounds sustained during } \\
\text { meal preparation }\end{array}$ & 27 & 8 & 21 & 21.1 & 0.93 \\
\hline 2 & Thawing or defrosting of food overnight & 27 & 11 & 12 & 2.3 & 0.84 \\
\hline 3 & $\begin{array}{l}\text { Cooking of food partially and completing cooking } \\
\text { later }\end{array}$ & 32 & 9 & 12 & 2.38 & 0.84 \\
\hline 4 & Use of pipe borne water for cooking preparation. & 30 & 20 & - & 2.60 & 0.49 \\
\hline 5 & $\begin{array}{l}\text { Using the same knife for different food without } \\
\text { washing }\end{array}$ & 20 & 12 & 15 & 2.11 & 0.87 \\
\hline 6 & Preparation of salad with bare hands & 21 & 6 & 12 & 2.23 & 0.90 \\
\hline 7 & Licking spoon as a means of tasting food & 17 & 10 & 18 & 1.98 & 0.89 \\
\hline 8 & Using well water to cook & 18 & 18 & 8 & 2.23 & 0.74 \\
\hline 9 & Using rain water for cooking meals & 9 & 39 & 6 & 2.06 & 0.53 \\
\hline 10 & Use of river water for cooking & 5 & 13 & 24 & 1.55 & 0.71 \\
\hline 11 & Keeping of leftover food for sometime before storage & 18 & 12 & 15 & 2.07 & 0.86 \\
\hline 12 & Not keeping perishable foods in refrigerator on time & 15 & 12 & 18 & 1.93 & 0.86 \\
\hline 13 & Warning of leftover food more than twice & 27 & 18 & 12 & 2.29 & 0.79 \\
\hline 14 & $\begin{array}{l}\text { Preparing meals and serving with rings on their } \\
\text { fingers }\end{array}$ & 24 & 19 & 2 & 2.49 & 0.59 \\
\hline 15 & Preparing meals with bracelets on & 12 & 14 & 16 & 1.90 & 0.82 \\
\hline 16 & $\begin{array}{l}\text { Wearing of dirty apron on during meal preparation } \\
\text { and service }\end{array}$ & 6 & 5 & 30 & 1.41 & 0.75 \\
\hline
\end{tabular}

Table 2 showed that item had their mean rating values to be 2.00 and above. This implies that the items were common unsafe meal preparation and service practices of the fast foods providers in Delta State. The other items with mean values below 2.00 are not common unsafe meal preparation and service practices by the fast foods providers.

\section{Discussion of Results}

The study investigated the meal preparation and service practices of fast food providers in Delta State, Nigeria. Some of such practices adopted always are as fellows - washing of hands with soap and clean water before and after meal preparation and before serving meals. These are good health practices capable of minimizing to a large extent the risk of introducing micro-organisms into food Richard stated that hands must be washed under warm running potable water [13]. Brook advised that food handlers should always wash their hands with warm soapy water especially after using toilet facilities blowing of nose, sneezing or coughing [3].

Some food providers stated that they prepare meals and serve with rings on their fingers and some wear bracelets. FAO advised on the need to avoid wearing rings, bracelet during handling of food [8]. This practice was done by both those food providers (those in the university campus and those outside the campus). This practice needs to be seriously 
discouraged. This is because dirt could stick to rings and bracelets to contaminate food. Dirt could be introduced to food unconsciously during meal preparation and service.

Some of the food providers usually wear apron during meal preparation and service. Some of the aprons worn were not clean. Richard emphasized the need for personal cleanliness [13]. He stated that personal hygiene must be maintained in food handling operations. He stressed the need for the wearing of sanitary protective clothes and that such clothing must be clean.

Another practice is the re-heating of only foods that will be served. This prevents overcooking of the entire food where the small portion was taken. The use of napkins to dry wet hands and cooking of meat sufficiently to kill germs are acceptable hygiene measures.

One of the food preparation and service measures is the avoidance of sneezing directly on food. Brook advised that food handlers should avoid sneezing directly on food [3]. When food handlers sneeze directly on food a lot of micro-organisms are transferred to contaminate the food.

Many of the food handlers often cut vegetables before washing. This practice is not appropriate. Such practice leads to loss of much of the nutrients in the water used for washing. The appropriate practice is to thoroughly wash leafy vegetables before cutting them. This practice prevents the loss of nutrients in the water used for washing vegetables.

Another food handling measure is cleaning of tables before and after food service. This prevents flies from petching on food on food. Antiseptic cleanser can be used to wipe table to minimize germs interring foods.

\section{Conclusion}

The study identified the food handling practices (meal preparation and service) of fast food providers in Delta State of Nigeria. It was found that some of the fast food providers adopt some hygienic measurers in food preparation/services and storage. Some of the food providers did not adopt safe food handling practices during service of food. The use of unsafe food handling practices could be a potential source of food contamination to the consumers. These indicate that these fast food providers need to be given Nutrition and Health Education in order to safeguard the lives of those who purchase and consume fast foods in Delta State.

\section{Recommendations}

1. The government should set up food inspectors to assess food safety practices of fast food providers in Delta State. These agents should monitor and educate fast food providers on food safety measures for good health.

2. Health Education in the area of hygiene (personal hygiene and in food handling) should be given to the fast food providers.

3. Nutrition Education should be given to the fast food providers on in Delta State. This will serve as a guide to the food providers to apply nutrition principles that will promote the nutritional status of the consumers.

4. The fast foods providers should be taught food selection and safe food storage.

5. The fast food providers should be taught by Nutritionists the various methods of meal preparation that conserve nutrients to enhance their nutritional status and that of the consumers.

6. The Delta State Government through the Ministry of Health should design a programme that is geared towards educating fast food providers on how to maintain maximum hygiene of themselves and in food selection, preparation of meals and service.

7. Public Health authorities in the Delta State through the assistance of Home Economists and Nutritionists should organize workshops for fast food providers. The workshop should focus on Nutrition and Health Education Emphasis should be on food selection and meal preparation and service. The food providers should be taught how to select nutritious foods and method of food and meal preparation that aim at maximum nutrient retention in order to improve their nutritional status and that of the consumers.

8. The government through the help of Nutritionists/Home Economists and qualified health officers (Nurses and medical doctors) to organize annual programme of training for fast food providers. The government should make attendance to be mandatory for all fast food providers. A certificate of attendance should be issued. Those who fail to attend such training should not be permitted to operate.

9. The state and local Government Authorities should set up standard in terms of Nutritional quality of food and hygiene so that after thorough screening license should be issued to only those fast food providers who meet the set up standard.

10. Working or preparation surfaces must be kept clean and made of impermeable material which is easy to clean.

11. The food providers should be taught how to maintain hygiene in food handling by Nutritionists and Health Educators. The personal hygiene of the food vendors should be examined and be given Health Education.

12. The use of disposable paper napkins should be encouraged instead of hand towels. The use of disposable paper napkins is more hygienic than cotton towels. 


\section{References}

[1] Achalu E.I. (2007) Communicable Diseases, Causes and Prevention. Sinach and Splendid Academic Publishers Lagos.

[2] Besnson A.S. (2008) Control of Communicable Diseases in Man. Washington American Puplic Health Association.

[3] Brook, H. (2001) "Food messages hit homes" Media Advisor, www.moh.govtn2- environmental health.

[4] Day F. and Sutton G. (2007) General Practitioner Notification of Gastroenteritis and Food Poisoning, Cause for Concern.

[5] Ene-Obong, H.N. (2001) Eating Right (A Nutrition guide) University of Calabar Press Calabar.

[6] Federal Ministry of Health (FMH) (2000) National Policy on Food Hygiene. Lagos, Nigeria.

[7] Food and Agricultural Organization (FAO) (1995) Technical Meetings on Street Foods.

[8] Food and Agricultural Organization (FAO) of the United States of America (2002) Improving Efficiency and Transparency in Food Services. Rome.

[9] Miller B. and Burt J.C. (2011) Good Health. London W.B. Sanders.

[10] Oghenekome, O.B. and Nwankwo T. (2006) Food Handling Practices in Hospitals in Uvwie Local Government Area of Delta State. Journal of Home Economics Research. Vol.7 Special Edition. Published by the Home Economics Research Association of Nigeria (RERAN).

[11] Ogowewo O.B. (2004) Effects of Food Hygiene Instruction on Home Economics Food Preparation Practices. Unpublished Ph.D Thesis. Delta State University, Abraka.

[12] Opponge J.A. (1999) A Breakthrough in Food Hygiene for WAEC Students. Adaranjo Publisher, Lagos.

[13] Richard, (2004) Bacteria and Food Borne Diseases, "www.csrecipes.com/articles/food poisoning.

[14] Schiosser E. (1998) Fast Food Nation: The Tree Cost of America's Diet. Rolling Stone Magazine (USA) Issue 794. September 31/1/1998.

[15] United Nations (UN) (2007) Working Together ends Child Hunger and Under Nutrition. United Kingdom 34, p. 10 .

[16] United States Food and Drug Administration (1995): FDA Consumer Magazine October 1995.

[17] World Health Organization (WHO) (2002) Impact of Nutrition on Health, Geneva.
[18] World Health Organization (WHO) Street Foods in Lagos, Nigeria, Vol. 9 (1) March to April. 